\title{
Comparative study of transdermal nitroglycerine patch vs. intramuscular isoxsuprine in treatment of preterm labour
}

\author{
Abhijeet Kokane*, Pundalik Sonawane
}

Department of Obstetrics \& Gynaecology, K. J. Somaiya Medical College, Mumbai, India

Received: 12 August 2015

Accepted: 02 September 2015

\author{
*Correspondence: \\ Dr. Abhijeet Kokane, \\ E-mail: dr_agkokane@rediffmail.com
}

Copyright: (C) the author(s), publisher and licensee Medip Academy. This is an open-access article distributed under the terms of the Creative Commons Attribution Non-Commercial License, which permits unrestricted non-commercial use, distribution, and reproduction in any medium, provided the original work is properly cited.

\begin{abstract}
Background: Preterm labour and delivery are very challenging obstetric complications encountered by obstetricians. Despite advances in perinatal medicine, the incidence continues to increase.so need for best tocolytic is necessary to reduce perinatal mortality associate with preterm birth.

Methods: A randomized prospective comparative study, carried out over a period of 24 months. 100 antenatal cases with 24-36 weeks of gestation randomly selected \& divided into two groups of 50 each. Group A: Treated with transdermal nitroglycerine patch (NITRODERM TTS-10 patch releasing 10mg / 24hr till 48 hrs.) \& Group B : Treated with intramuscular isoxsuprine (Inj). Duvadilan $10 \mathrm{mg} / 8 \mathrm{hrly}$ till $48 \mathrm{hrs}$.) after treatment in both groups Patients started on capsule Duvadilan retard (40mg) OD for one more week. Data collected regarding efficacy of the drugs in terms of Maternal side effects, Fetal side effects, prolongation of pregnancy for (48 hrs/ 48-72 hrs/3-7 days/> 7 days), Changes in cervical dilatation and cervical length after 48 hrs, Mode of delivery, Gestational weeks at the time of delivery, Neonatal outcome.

Results: In our study there was no statistically significant difference in demographic data, risk factors, gestational age at admission, obstetric score, fetal side effects, prolongation of pregnancy, cervical length changes, successful tocolysis, gestational age at delivery, mode of delivery, neonatal outcome But Mean cervical dilatation changes after $48 \mathrm{hrs}$. of tocolytic treatment in these two groups were statistically significant $(0.14 \mathrm{vs} .0 .19, \mathrm{p}$ value $=0.024)$ where nitroglycerine is more effective. Headache was exclusively seen in $80 \%$ patients of nitroglycerine group \& tachycardia and palpitation exclusively seen in $88 \%$ patients of isoxsuprine group, where difference is statistically significant ( $\mathrm{p}$ value $=0.0001)$.

Conclusions: Nitroglycerine patch should be recommended over intramuscular isoxsuprine for all preterm labour patients including threatened preterm as it appears to be better tolerable in term of treatable side effect \& better acceptable than painful multiple intramuscular injections of isoxsuprine.
\end{abstract}

Keywords: Nitroglycerine, Isoxsuprine, Preterm, Tocolytic

\section{INTRODUCTION}

Preterm labour is defined as the onset of labour after the age of viability (20-24) and before 37 completed weeks of pregnancy and its incidence is $6-10 \%$ of all births in developed countries. ${ }^{1}$ It is common in patients with low body weight, low stature, unsupported mothers, smokers and lower social classes. ${ }^{2}$ Risk factors that have been linked to preterm delivery include cervical incompetence, haemorrhage like placental abruption, genital tract infection like bacterial vaginosis, hormonal changes due to maternal or foetal stress, multifetal pregnancy and previous history of preterm labour. ${ }^{3}$

Incidence of preterm labour is $23.3 \%$ and of preterm delivery $10-69 \%$ in India. ${ }^{4}$ It is raising worldwide because of increased frequency of multiple births due to 
assisted reproductive techniques (ART), more working mothers, increasing psychological stress and medically induced prematurity. ${ }^{4}$ Hence the aim of the treatment for preterm delivery is to suppress the uterine contractions so as to delay the pre-term birth to allow administration of complete course of corticosteroids in order to reduce incidence of respiratory distress syndrome and to subsequently arrange in utero transfer to a center with neonatal intensive care unit facility to reduce perinatal morbidity and mortality associated with severe prematurity. ${ }^{1}$

For this purpose a wide variety of agents have been advocated like beta agonists, calcium channel blockers, prostaglandin synthetase inhibitors, magnesium sulphate and also oxytocin receptor antagonists. ${ }^{5}$ Most of these drugs require strict monitoring of both mother and foetus due to their adverse effects. ${ }^{1}$

Isoxsuprine is beta adrenergic agonist that causes direct relaxation of uterine \& vascular smooth muscle. Its vasodilatory actions are greater on the arteries supplying skeletal muscle than on those supplying skin. While nitroglycerine act by reducing corticotrophin releasing hormone secretion $(\mathrm{CRH})$.

\section{METHODS}

This is a randomized prospective comparative study, carried out in the department of Obstetrics and Gynaecology of K. J. SOMAIYA MEDICAL COLLEGE AND RESEARCH INSTITUTE, MUMBAI over a period of 24 months - from December 2011 to November 2013.

During a study period, 100 antenatal cases with 24-36 weeks of gestation randomly selected for study depending on following inclusion and exclusion criteria. Inclusion criteria include Pregnancy with gestational age 24 wks. To 36 wks. Uterine activity: > 3 contractions in 30 min., Cervical dilatation: os closed to $3 \mathrm{~cm} \&$ Intact membranes. While Exclusion criteria includes Pregnancy with gestational age less than 24 wks. \& more than 36 wks., Active labour with more than $3 \mathrm{~cm}$ cervical dilatation, Leaking per vaginum, Evidence of chorioamnionitis (i.e. fever, tachycardia, uterine tenderness, foul smelling discharge per vaginum) Pregnancy with fetal malformation, intra uterine fetal death \& Contraindication for use of nitroglycerine \& isoxsuprine such as known hypersensitivity, heart diseases, antepartum haemorrhages, severe anaemia, uncontrolled diabetes

Method of study:- A detailed history taken, dates confirmed, risk factors such as smoking, tobacco chewing, alcohol, coitus, anaemia, infection(increase in serum TLC, pus cells in urine), past h/o preterm labour, past h/o 2nd trimester abortion, cervical surgery, polyhydramnios, multiple pregnancy, Rh isoimmunisation, uterine anomalies identified. Complete physical examination done. Vital baseline parameters like pulse, BP, temperature were recorded. Detailed per abdomen, per speculum and per vaginal examinations were done. The following investigations were done in the study subjects as soon as diagnosis was established: Hemoglobin \%, Complete blood count, Urine routine and microscopy, Ultrasonography for viability, fetal biometry, placenta localization, AFI, cervical length \& internal OS status done.

After inclusion \& exclusion criteria met, these randomly selected eligible patients were divided into two groups

Group $\boldsymbol{A}$ - 50 Patients treated with transdermal nitroglycerine patch

Group B - 50 Patients treated with intramuscular isoxsuprine injection

Informed valid written consent was taken.

All patients enrolled in study were given inj. betamethasone (12mg) IM 2 doses $24 \mathrm{hrs}$. apart \& IV antibiotics, inj. Baxim (500mg) BD \& inj. Metrogyl TDS for $24 \mathrm{hrs}$. given.

Flow chart of participant selection and randomization:

118 women with preterm labour assessed in study period

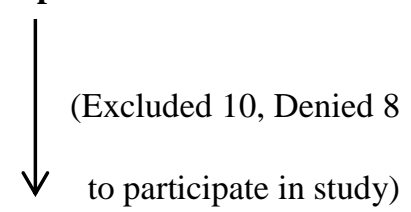

100 women enrolled for study \& randomized

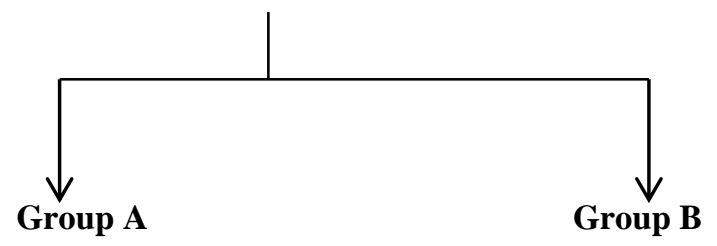

50 patients received transdermal NTG patch.<smiles></smiles>

Analyzed 50 patients

50 patients received intramuscular isoxsuprine.

\section{Treatment protocol:}

Group A - Treated with transdermal nitroglycerine patch

Single nitroglycerine patch with brand name NITRODERM TTS 10 containing $50 \mathrm{mg}$ of nitroglycerine which was released over a period of $24 \mathrm{hrs}$. was applied transdermally on anterior abdominal wall. The patch was removed after 24 hours and fresh patch applied for another $24 \mathrm{hrs}$. To avoid expected 
hypotensive effect of transdermal nitroglycerine patch, prophylactic infusion of $500 \mathrm{ml}$ of normal saline given to all the patients in the study group. Headache if occurred in nitroglycerine group is treated with T. paracetamol 500 mg single dose.

Group B - Treated with Intramuscular Isoxsuprine Injection

Intramuscular isoxsuprine with brand name Inj. 'Duvadilan' containing $10 \mathrm{mg}$ isoxsuprine hydrochloride administered as intramuscular injection 8 hourly till 48 hrs.

Monitoring done by measuring Baseline temp, pulse, blood pressure, FHS, uterine contraction. Half hourly abdominal palpation done to note frequency and strength of uterine contractions for 2 hours, hourly for next $4 \mathrm{hr}$. , four hourly for next $18 \mathrm{hrs}$. and then 6 hourly for next 24 hrs. Pulse, BP, fetal heart rate monitoring every $15 \mathrm{~min}$ for 2 hours, hourly for next 4 hrs., four hourly for $18 \mathrm{hrs}$. and then 6 hourly for next $24 \mathrm{hrs}$. Close monitoring done for maternal side effects such as headache, palpitation, flushing, giddiness, and some side effect specific to transdermal nitroglycerine patch like local irritation. \& Fetal side effects such as fetal distress i.e. FHS $<110$ bpm and fetal tachycardia i.e. FHS > $150 \mathrm{bpm}$. Per vaginal examination done if uterine contractions persist for $>12 \mathrm{hrs}$. or clo leaking per vaginum or after $48 \mathrm{hrs}$. \& cervical length assessment by USG repeated after $48 \mathrm{hrs}$.

Treatment was discontinued in both the groups if there was Maternal tachycardia greater than 120 beats/minute, Drop of blood pressure by $15 \mathrm{~mm}$ of $\mathrm{Hg}$ or more from baseline diastolic pressure, Signs and symptoms suggestive of pulmonary oedema such as breathlessness, cough with expectoration.

Patients were discharged 48 hrs. after uterine contractions subsided and started on oral beta mimetic isoxsuprine (40mg) sustained release capsule continued till one more week and patient assessed antenatally every week until delivery.

Successful endpoint: Treatment was considered successful if uterine contractions subsided and thus tocolysis achieved for more than 48 hours.
Data collected regarding efficacy of the drugs in terms of Maternal side effects, Fetal side effects, Prolongation of pregnancy for $48 \mathrm{hrs}$., Changes in cervical dilatation and cervical length after 48 hrs., Prolongation of pregnancy, Mode of delivery, Gestational age at the time of delivery, Neonatal outcome \& birth weight.

\section{RESULTS}

Total number of deliveries during the study period was 3126 , Total number of preterm labour cases was 292, and therefore Incidence of preterm labour was $9.34 \%$.

In our study, majority of patients (38\%) are from age group 16-20 yrs. More than $60 \%$ of the study population was illiterates in both groups $(64 \%$ vs. 66\%).Total illiterate patients were 65 out of 100 i.e. $65 \%$.Patients were categorized in different class depending upon kuppuswamy's6 classification. Majority of the patients in our study came from lower socioeconomic status in both groups $(30 \%$ vs. $26 \%)$. In our study, incidence of preterm labour was more in primigravida $(56 \%)$ than multigravida (44\%). Majority of the patients in our study were between 31-33.6 weeks of gestation $44 \%$ in nitroglycerine group and $48 \%$ isoxsuprine group respectively. The mean gestational age at admission in nitroglycerine group and isoxsuprine group is $32.53 \pm$ 1.6391 and $32.09 \pm 1.9696$ weeks respectively. In our study commonest risk factor in nitroglycerine and isoxsuprine groups is anaemia (18 \% vs. $20 \%$ respectively), followed by infection ( $12 \%$ vs. $18 \%$ respectively) among total 15 patients of infection $10(66.66 \%)$ patients had UTI. History of preterm labour (4\% vs. $8 \%$ respectively) and polyhydramnios (4\% vs. $6 \%$ respectively) and etc.

In patients with successful tocolysis, mean cervical dilatation changes in nitroglycerine group is $0.14 \pm 0.64$ $\mathrm{cm}$ and in isoxsuprine group it is $0.19 \pm 0.89 \mathrm{~cm}$, which is statistically significant ( $\mathrm{p}$ value $=0.024$ ) as shown in Table no. 1 but there are no statistically signicant changes seen in ultrasound estimation of cervical length (on admission \& $48 \mathrm{hrs}$. after starting therapy) as shown in Table no. 2 .

Table 1: Changes in cervical dilatation.

\begin{tabular}{|llll|}
\hline \multirow{2}{*}{ Cervical dilatation $(\mathrm{cm})$} & & Nitroglycerine group & Isoxsuprine group \\
\hline At admission $(\mathrm{N}=50, \mathrm{I}=50)$ & Mean & 1.08 & 1.15 \\
\cline { 2 - 4 } & Standard deviation & 0.81 & 0.85 \\
\hline \multirow{2}{*}{ After 48 hrs. $(\mathrm{N}=49, \mathrm{I}=48)$} & Mean & 1.22 & 1.34 \\
\cline { 2 - 4 } & Standard deviation & 1.1 & 1.26 \\
\hline \multirow{2}{*}{ Dilatation changes $(\mathrm{N}=49, \mathrm{I}=48)$} & Mean & 0.14 & 0.19 \\
\cline { 2 - 4 } & Standard deviation & 0.64 & 0.89 \\
\hline
\end{tabular}


Table 2: Changes in cervical length.

\begin{tabular}{|c|c|c|c|c|c|}
\hline \multicolumn{2}{|c|}{ Cervical length } & Nitroglycerine group & Isoxsuprine group & \multicolumn{2}{|l|}{ Statistics } \\
\hline \multirow{2}{*}{$\begin{array}{l}\text { At } \\
\text { admission } \\
(\mathrm{N}=50, \mathrm{I}=50)\end{array}$} & Mean & 2.788 & 2.814 & \multirow{2}{*}{$\mathrm{P}$ value $=0.670$} & \multirow{6}{*}{$\begin{array}{l}\text { Test applied: } \\
\text { Independent T-test }\end{array}$} \\
\hline & Standard deviation & 0.3173 & 0.2900 & & \\
\hline \multirow{2}{*}{$\begin{array}{l}\text { After } 48 \text { hrs. } \\
(\mathrm{N}=49, \mathrm{I}=48)\end{array}$} & Mean & 2.69 & 2.64 & \multirow{2}{*}{$\mathrm{P}$ value $=0.675$} & \\
\hline & Standard deviation & 0.566 & 0.657 & & \\
\hline \multirow{2}{*}{$\begin{array}{l}\text { Cervical } \\
\text { length } \\
\text { changes } \\
(\mathrm{N}=49, \mathrm{I}=48)\end{array}$} & Mean & 0.1122 & 0.1979 & \multirow[b]{2}{*}{$\mathrm{P}$ value $=0.369$} & \\
\hline & Standard deviation & 0.38223 & 0.54009 & & \\
\hline
\end{tabular}

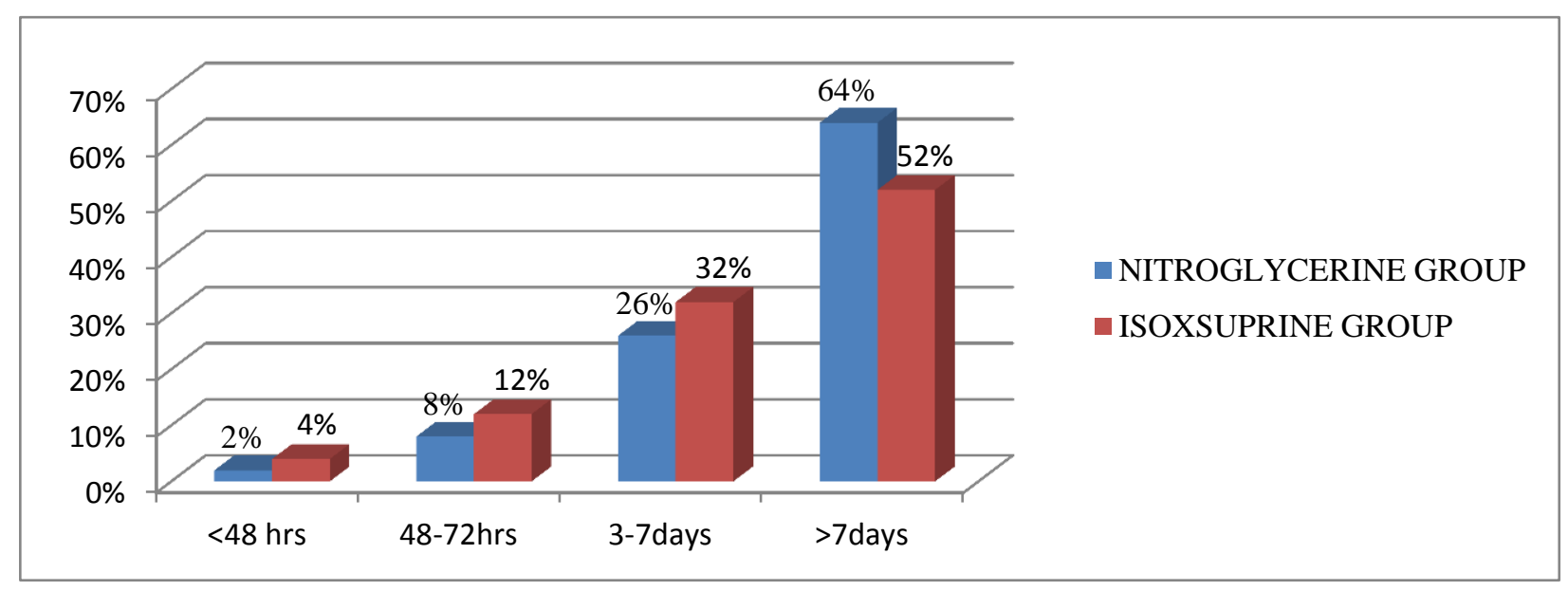

Figure 1: No. of Patients delivered.

Table 3: Success or failure of tocolysis.

\begin{tabular}{|c|c|c|c|c|c|}
\hline & \multicolumn{2}{|c|}{ Nitroglycerine group } & \multicolumn{2}{|c|}{ Isoxsuprine group } & Statistics \\
\hline & No. of patients & $\%$ & No. of patients & $\%$ & \multirow{2}{*}{ Test applied: Fisher's exact test } \\
\hline Successful tocolysis & 49 & $98 \%$ & 48 & $96 \%$ & \\
\hline Failure of tocolysis & 1 & $2 \%$ & 2 & $4 \%$ & \multirow{2}{*}{$\mathrm{P}$ value $=>0.99$} \\
\hline Total & 50 & $100 \%$ & 50 & $100 \%$ & \\
\hline
\end{tabular}

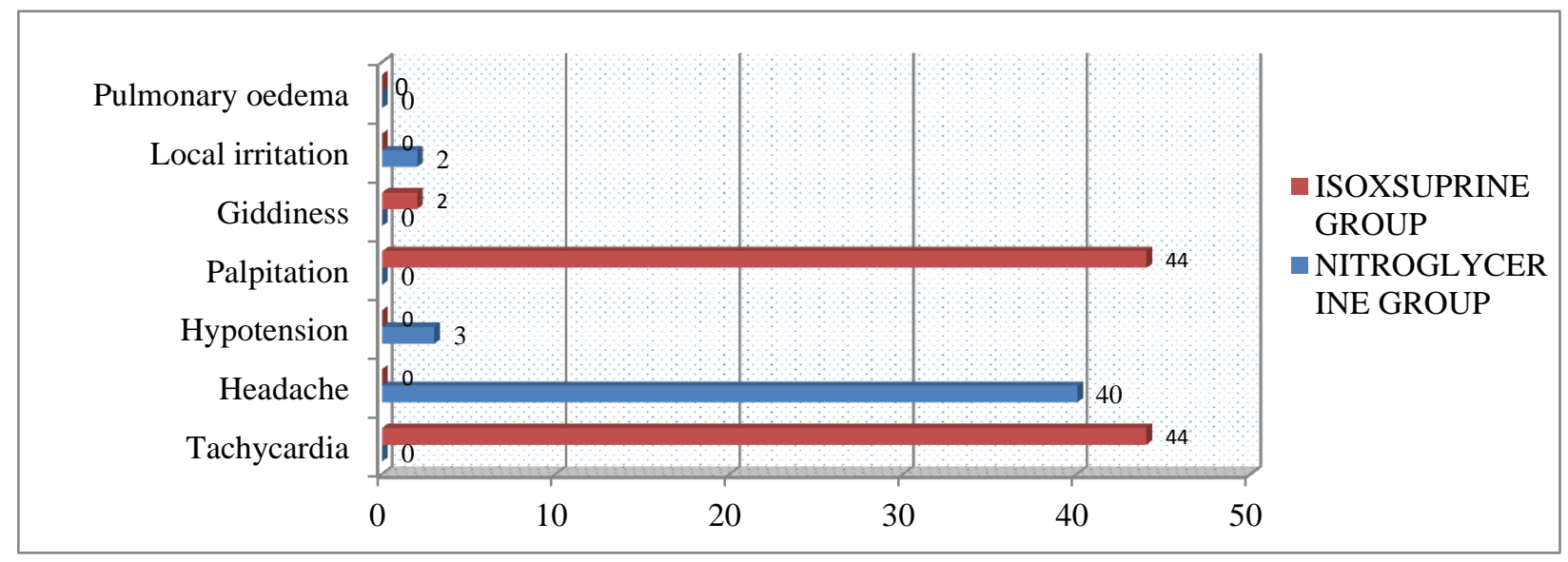

Figure 2: Maternal side effects. 
Fetal distress (FHS $<110 \mathrm{bpm}$ ) was seen in 1 out of 50 patients of nitroglycerine group and 1 out of 50 patients of isoxsuprine group, Fetal tachycardia (FHS>150 bpm) was seen in 5 out of 50 patients of nitroglycerine group and 7 out of 50 patients of isoxsuprine group , the difference is not statistically significant.

Number of patients delivered in <48hrs / 48 -72 hrs / 3-7 days $/>7$ days is comparable i.e. prolongation of pregnancy is similar in both groups and statistically not significant as shown in Figure no. 1. Mean duration of prolongation of pregnancy in nitroglycerine group was $24.32 \pm 19.611$ days and in isoxsuprine group was 20.52 \pm 17.561 days but difference was statistically not significant. In our study tocolysis therapy is successful in $98 \%$ cases in nitroglycerine group as compared to $96 \%$ success rate of isoxsuprine group. But difference is statistically not significant (Table no. 3).

Table 4: Maternal side effects.

\begin{tabular}{|c|c|c|c|c|c|c|}
\hline \multirow[t]{2}{*}{ Side effects } & \multicolumn{2}{|c|}{ Nitroglycerine group } & \multicolumn{2}{|c|}{ Isoxsuprine group } & \multirow{2}{*}{\multicolumn{2}{|c|}{ Statistics }} \\
\hline & No. of pts. & $\%$ & No. of pts. & $\%$ & & \\
\hline Tachycardia & 0 & $0 \%$ & 44 & $88 \%$ & $P$ value $=0.0001$ & \multirow{3}{*}{$\begin{array}{l}\text { Test applied: Pearson's } \\
\text { Chi-square tests }\end{array}$} \\
\hline Headache & 40 & $80 \%$ & 0 & $0 \%$ & $P$ value $=0.0001$ & \\
\hline Palpitation & 0 & $0 \%$ & 44 & $88 \%$ & $P$ value $=0.0001$ & \\
\hline Hypotension & 3 & $6 \%$ & 0 & $0 \%$ & $\mathrm{P}$ value $=0.242$ & \multirow{3}{*}{$\begin{array}{l}\text { Test applied: Fisher's } \\
\text { exact test }\end{array}$} \\
\hline Giddiness & 0 & $0 \%$ & 2 & $4 \%$ & $\mathrm{P}$ value $=0.495$ & \\
\hline Local irritation & 2 & $4 \%$ & 0 & $0 \%$ & $\mathrm{P}$ value $=0.495$ & \\
\hline Pulmonary oedema & 0 & 0 & 0 & 0 & & \\
\hline
\end{tabular}

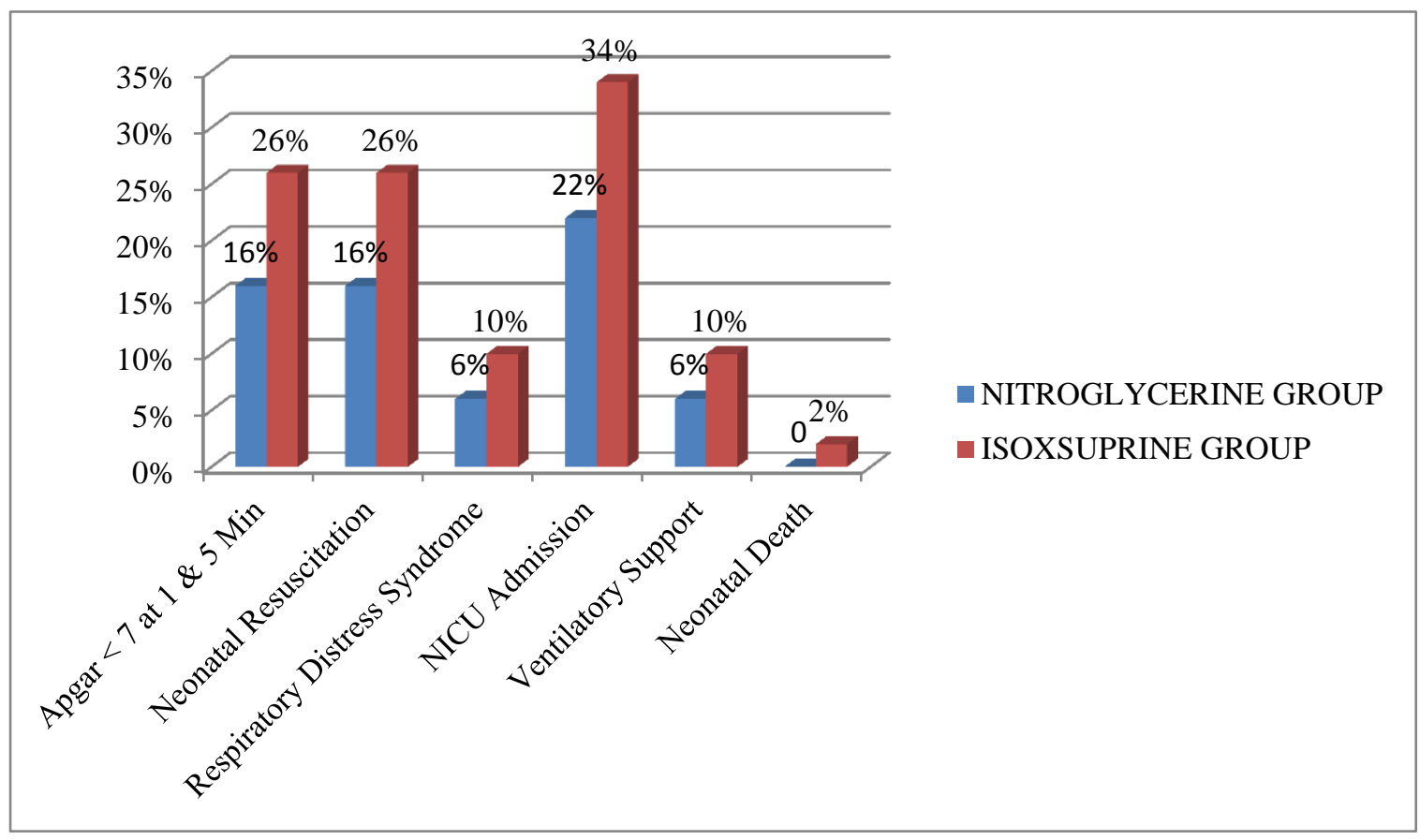

Figure 3: Neonatal Outcome.

In our study, out of 50 patients, headache was noted in $40(80 \%)$ patients of nitroglycerine group as compared to isoxsuprine group where none of them had Headache. Here $p$ value is $<0.05$ that is statistically significant. Out of 50 patients, tachycardia and palpitation were noted in $44(88 \%)$ patients of isoxsuprine group as compared to nitroglycerine group where neither of them tachycardia nor palpitation had. Here $\mathrm{p}$ value is $<0.05$ that is statistically significant. Other side effects like giddiness noted in $2(4 \%)$ patients of isoxsuprine group and hypotension and local irritation noted in $3(6 \%)$ and $2(4 \%)$ patients of nitroglycerine group respectively. Difference in these side effects is statistically not significant. No other serious side effects noted in both groups. As shown in Table no. 4 \& Figure no. 2 
Mean gestational age at delivery in nitroglycerine group was $36.16 \pm 2.645 \mathrm{wks}$. and in isoxsuprine group was $35.16 \pm 2.930$ wks. Difference is statistically not significant. Patients delivered beyond 37 weeks were $38 \%$ in NTG group and $26 \%$ in isoxsuprine group. Out of 50 patients in nitroglycerine group, 38 patients $(76 \%)$ and out of 50 patients in isoxsuprine group, 36 patients (72\%) delivered vaginally. 9 patients $(18 \%)$ in nitroglycerine group and11 (22\%) patients in isoxsuprine group required caesarean section. In both groups 3 patients $(6 \%)$ delivered vaginally by instrumental delivery. Difference is statistically not significant.

In our study, mean birth weight of infants delivered is $2.506 \pm 0.42877 \mathrm{~kg}$ in nitroglycerine group and $2.34 \pm$ $0.44309 \mathrm{~kg}$ in isoxsuprine group. This difference is statistically not significant. Overall mean birth weight is $2.423 \mathrm{~kg}$. Difference in the variable of neonatal outcome was statistically not significant \& comparable in both groups as shown in Figure no.3.

\section{DISCUSSION}

Successful tocolysis is defined as prolongation of preterm labour beyond $48 \mathrm{hrs}$. and failure of tocolysis is defined as delivery within 48 hours. In patients with successful tocolysis, mean cervical dilatation changes in nitroglycerine group is $0.14 \pm 0.64 \mathrm{~cm}$ and in isoxsuprine group it is $0.19 \pm 0.89 \mathrm{~cm}$, which is statistically significant. Even the mean cervical dilatation changes in nitroglycerine group was statistically significant compared to isoxsuprine group, it is not clinically significant as it was not crossing $>3 \mathrm{~cm}$ cervical dilatation. In our study, majority of patients have insignificant mean cervical length (effacement) changes, thus indicating successful tocolysis. This was seen in both the groups. Thus mean cervical length compared in both group and it was not significant hence both the drugs are equally good in halting progression of cervical length.

In our study we get mean prolongation of pregnancy in nitroglycerine group by $24.32 \pm 19.611$ days which is comparable with study conducted by $\mathrm{He} \mathrm{Q}$ et $\mathrm{al}^{7}$ and Smith et $\mathrm{al}^{8}$ which is 25 days and 23 days respectively. So mean prolongation of pregnancy with nitroglycerine is comparable with above mentioned studies. While mean prolongation of pregnancy in our study was $20.52 \pm$ 17.561 days with intramuscular isoxsuprine. This result was similar to those reported by Rayamajhi et al9 study. Rayamajhi et $\mathrm{al}^{9}$ reported mean prolongation of pregnancy as 19.18 days with isoxsuprine. So mean prolongation of pregnancy with isoxsuprine is comparable with above mentioned studies.

In our study success rate is $98 \%$ in patients treated with nitroglycerine patch. Success rate of transdermal nitroglycerine is comparable with study conducted by Sachan Rekha et al. ${ }^{10}(98 \%)$. In our study success rate is $96 \%$ in patients treated with isoxsuprine \& is comparable with study conducted by Sachan Rekha et al. ${ }^{10}$ Success rate is comparable with above mentioned study. In nitroglycerine group, out of 50 patients, 1 patient $\&$ in isoxsuprine group, out of 50 patients, 2 patients who delivered were already 2.5 to $3 \mathrm{~cm}$ dilated with good uterine activity. So to prevent preterm delivery we should pick up preterm in early stage.

In our study, headache was exclusively seen in nitroglycerine group in which it occurred in $80 \%$ of patients, headache is relieved by giving oral T.paracetamol and all patients responded to paracetamol tablet. Local irritation occurred in $4 \%$ patients and hypotension in $6 \%$ patients. In our study, tachycardia and palpitation were exclusively seen in isoxsuprine group in which both occurred in $88 \%$ of patients and giddiness in $4 \%$ patients. None of the patient had pulmonary edema. In a study conducted by Sachan Rekha et al (2012), ${ }^{10}$ headaches are exclusively seen in nitroglycerine group in $100 \%$ cases while tachycardia and palpitation are exclusively seen in isoxsuprine group $100 \%$. So our study is comparable with above mentioned study as headache is exclusive side effect of nitroglycerine group and tachycardia and palpitation are exclusive side effects of isoxsuprine group.

\section{CONCLUSIONS}

Nitroglycerine and isoxsuprine, both drugs are effective in controlling uterine activity and thus preterm labour for first 48 hrs. To be effective, both nitroglycerine and isoxsuprine drug should be started in early preterm labour. Hence preterm labour should be diagnosed as early as possible.

Although nitroglycerine and isoxsuprine are safe and effective drugs in preventing preterm labour, nitroglycerine appears to be better tolerated by patients as compared to intramuscular isoxsuprine. Headache which is seen in nitroglycerine group is treatable with tablet paracetamol and is better tolerable than tachycardia and palpitation which are common side effects of isoxsuprine. Nitroglycerine as a single dose patch application per day is better acceptable than multiple intramuscular injections of isoxsuprine. Hence, nitroglycerine patch should be the first choice of tocolytic agent for all preterm labour patients including threatened preterm, especially for first 48 hrs.

\section{ACKNOWLEDGEMENT}

I would like to express my sincerest respect and gratitude to Dr. Pundalik Sonawane, Professor for his guidance.

I am highly indebted to Dr. Kamlesh Chaudhari, professor and Head of the Department, Obstetrics \& Gynaecology and Dr. Geeta Niyogi, Dean, K. J. Somaiya Hospital, who has kindly allowed me to carry out this work in her Department. 
Some debts in life are beyond acknowledgement. I express the most sincere gratitude to my parents, for giving me constant moral support during this period.

Last, but not the least, I thank all the patients enrolled in the study, who have readily cooperated and participated in this study.

\section{Funding: No funding sources}

Conflict of interest: None declared

Ethical approval: The study was approved by the Institutional Ethics Committee

\section{REFERENCES}

1. Junejo N, Mumtaz F, Unar BA. Comparasion of salbutomol and nefidepine as a tocolytic agent in the treatment of preterm labour. J Liaquat Uni Med Health Sci. 2008;7:115-9.

2. Ghazi A, Jabbar S, Siddiq NM. Preterm Labour stills a challenge. Pak J Surj. 2006;22:222-6.

3. Bennete P. Preterm Labour. In: Edmond DK, editors. Dewhursts Text book of obstetrics and gynecology. 7th ed. Blackwell Publishing Ltd, 2007;21:117-91.

4. Singh Uma, Singh Nisha, Seth Shikha. Department of Obstetrics and Gynecology, KGMU, Lucknow (UP). A prospective analysis of etiology and outcome of preterm labour. J Obstet Gynecol India. 2007;57(1):48-52.
5. De Renzo GC, Roura LC. Guideline for the management of preterm labour: international guideline. Berlin. New York: Walter de Gruter 2006;34:359-66.

6. Kuppuswamy B. Manual of Socioeconomic Status (Urban), 1 st ed. Delhi: Manasayan; 1981; p. 66-72.

7. He Q, Sha J, Gu Q, Gu H, Chen X, Yang Z, Ning H. [Clinical effect and mechanism of nitroglycerin patch on arresting preterm labour]. Zhonghua Fu Chan Ke Za Zhi. 2002;37(3):134-5.

8. Smith GN, Guo Y, Wen SW, Walker MC; Canadian Preterm Labour Nitroglycerin Trial Group. Secondary analysis of the use of transdermal nitroglycerin for preterm labour. Am J Obstet Gynecol. 2010;203(6):565.e1-6.

9. Rayamajhi R, Pratap K. A comparative study between Nifedipine and Isoxsuprine in the suppression of preterm labour. Kathamandu university medical journal 2003;1(2):85-90.

10. Sachan Rekha et al. Clinical Evaluation of Transdermal Nitroglycerine in Preterm Labour in tertiary care teaching hospital in India. International Journal of Scientific and Research Publications, March 2012; Volume 2:Issue 3.

Cite this article as: Kokane A, Sonawane P. Comparative study of transdermal nitroglycerine patch vs. intramuscular isoxsuprine in treatment of preterm labour. Int J Reprod Contracept Obstet Gynecol 2015;4:1471-7. 